\title{
Effect of Pressure on the Performance of Passive Two-Phase Closed Thermosyphon System Using R-134a
}

\author{
Abdelrahim Abusafa ${ }^{1, a}$ and Aysar Yasin ${ }^{2}$ \\ ${ }^{1}$ Chemical Engineering Department, An- Najah National University, Nablus P.O. Box:7, Palestine \\ ${ }^{2}$ Energy Engineering and Environment Department. An- Najah National University Nablus, P.O. Box:7, Palestine \\ ${ }^{a}$ corresponding author: email: abusafa@ najah.edu \\ https://doi.org/10.33976/JERT.7.1/2020/1
}

\begin{abstract}
Two-phase closed thermosiphon system for cooling high heat flux electronic devices was constructed and tested on a lab scale. The performance of the thermosyphon system was investigated using R-134a as a working fluid. The effect of heat flux and the refrigerant pressure on the evaporator side heat transfer coefficient were investigated. It was found that the heat transfer coefficient increases by increasing the heat flux on the evaporator or by reducing the inside pressure. The effect of heat transfer mode of the condenser (natural or forced) also affected the overall heat transfer coefficient in the cycle. At the $200 \mathrm{~W}$ heating load, the values of the heat transfer coefficients were 32 and $1.5 \mathrm{~kW} / \mathrm{m}^{2}$. ${ }^{\circ} \mathrm{C}$, for natural and forced convection modes, respectively.

The temperature difference between the evaporator and the refrigerant saturation pressure was found to be dependent on heat flux and the pressure inside the system. At $40 \mathrm{~W}$ heating load, the heat transfer coefficient was calculated to be 500,3000 and $7300 \mathrm{~W} /{ }^{\circ} \mathrm{C} \cdot \mathrm{m}^{2}$ at $0.152, .135$ and 0.117 reduced pressure, respectively. It can be concluded that such a thermosyphon system can be used to cool high heat flux devices. This can be done using an environmentally friendly refrigerant and without any need for power to force the convection at the condenser.
\end{abstract}

Index Terms: heat transfer coefficient; two-phase closed-loop thermosyphon; R-134a; forced and natural convection.

\section{INTRODUCTION}

The heat dissipation of electronic components is growing. The traditional air-cooling is ineffective. It is bounded to dissipate heat at $0.05 \mathrm{~W} / \mathrm{cm}^{2}$ rate. Higher air velocity or a considerably larger-dissipation area is required in case of encountering higher heat flux rates [1]. The thermal design must consider the system size, insert more components within limited space and reduce the system acoustic noise generated from the heat sinks fans. The thermal solution is required to dissipate the maximum power consumption of the electronic equipment and make it below its maximum operating temperature.

Liquids have much higher thermal conductivities than gases. Therefore, liquid cooling is more effective than gas cooling. Two-phase heat transfer technologies are used for cooling high heat flux devices such as heat pipes [2-6]. Capillary pumped loops and thermosyphons are commonly applied to cooling microelectronic components and devices [7].

The closed-loop thermosyphon is a simple structure and reliable. It is efficient for transferring heat in long distances with a slight reduction in temperature [8]. A cooling system based on a loop thermosyphon type composed mainly of a heating block, an evaporator, and an air-cooled condenser was inspected experimentally [9]. An efficient and small passive cooling two-phase systems with advanced micro-thermosyphon cooling systems were investigated [10].

In this paper, the passive closed-loop two-phase thermosyphon system was investigated. In this technology no power was needed to transfer heat and high heat flux could be dissipated.

The two-phase thermosyphon passive system is a gravity-dependent and wickless heat pipe. The system principally consists of an evaporator, condenser, and risers. The evaporator is attached directly to the hot component. The condenser should be above the evaporator to exploit the gravity that made the condensate easily back to the evaporator. The riser copper tube was connected to the top part of the evaporator and the down-comer copper tube.

The circulation in the evaporator was initiated when the working fluid heated up and reached boiling conditions. The net driving head caused by the difference in density between the liquid in the down-comer and vapor/liquid mixture in the riser should be able to overcome the pressure drop caused by the mass flow. The vapor bubbles 
started to form at the design temperature. When the working fluid became vapor, its density reduced and left the evaporator to the condenser. This happens via the riser tube where it got condensed and found its way to the evaporator via the down-comer to start new circulation.

The purpose of this research was to investigate the effect of pressure on heat transfer, heat transfer coefficients, and overall heat transfer coefficients. The effect of different types of microstructures on the performance of the closedloop thermosyphon system had been studied in $[4,8,11]$. The flow and heat transfer in a closed-loop thermosyphon had been studied theoretically and experimentally in [5-8], and [ 12-13].

The pressure drop in riser and evaporator in an advanced two-phase thermosiphon loop had been investigated experimentally [14, 15]. It had been found that the total pressure drop in the riser was the sum of the gravitational and frictional pressure drop $[14,15]$.

Pressure in a closed two-phase thermosiphon loop had a significant effect on the boiling heat transfer coefficient in the narrow channels of the thermosyphon evaporator [1]. Increasing pressure level generally led to lower temperature difference and smaller tubing diameter [16].

The thermal performance of a thermosyphon filled with $\mathrm{R}-134 \mathrm{a}$ had been studied in [17]. It was found that the performance of the R-134a thermosyphon increased with high coolant mass flow rates. The high filling ratios and the greater temperature difference between bath and condenser affect the performance as well [17]. Pressure has a great influence on critical heat flux (CHF) [18]. It was found also that limit critical heat flux decreased with an increase in pressure but increased with an increase in diameter [18].

This paper is arranged as follows: Section 2 describes the thermosyphon system components. Section 3 illustrates the research methodology. Section 4 presents the analysis and discussion of the results. The conclusion of the study is presented in section 5 .

\section{COOLING SYSTEM COMPONENTS}

The research results were based on an experimental setup built in the laboratory [2]. The main components were evaporator, condenser, riser pipe, down-comer pipe, seven thermocouples for temperature measurements, four pressure gauges for pressure measurements, two heating elements with potentiometers and suitable insulators.

Fig.1 illustrates the experimental setup of the investigated thermosyphon system. The system components and used materials details are shown below:

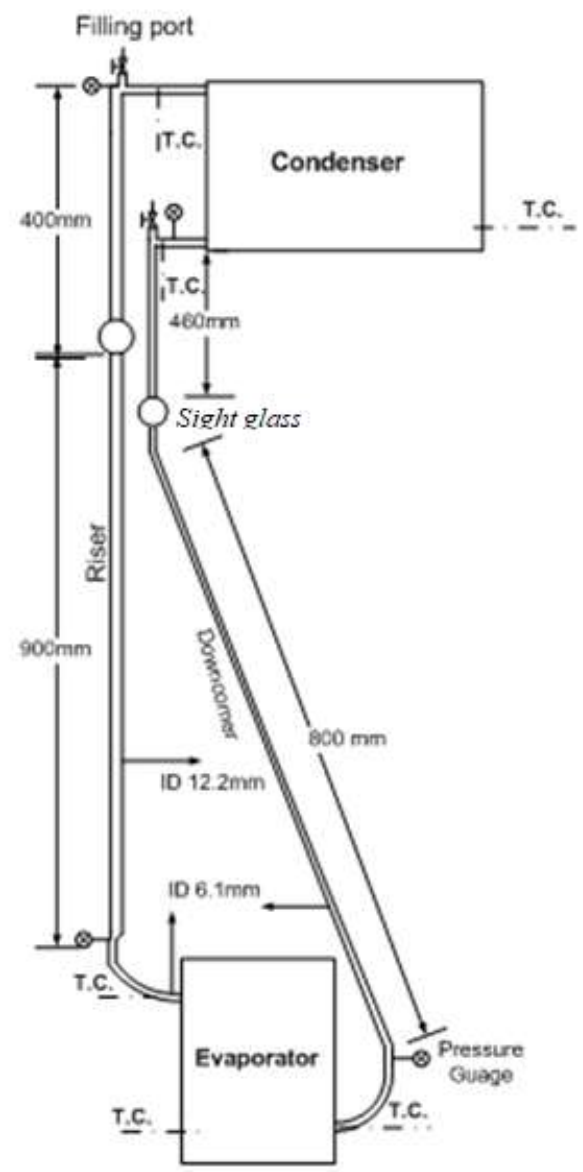

Fig.1. Schematic diagram of the tested thermosiphon system

2.1 Evaporator: The tested evaporator was made from copper and the weight was 440 grams. The outer dimension of the evaporator was $63 \times 50 \times 20$ as shown in Fig. 2.

The internal design of channels and the top view of the tested evaporator are illustrated in Figs 3 and 4, respectively. 


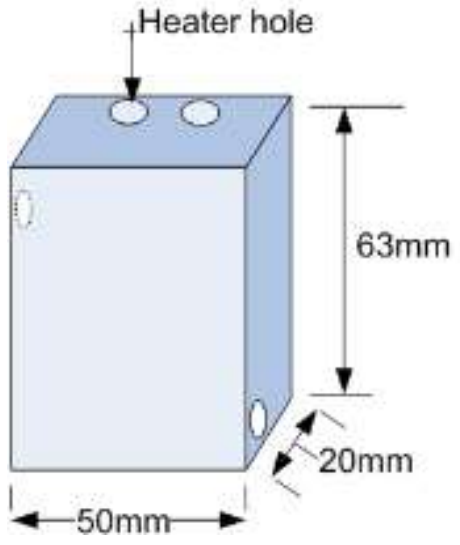

Fig.2. The external shape of the evaporator

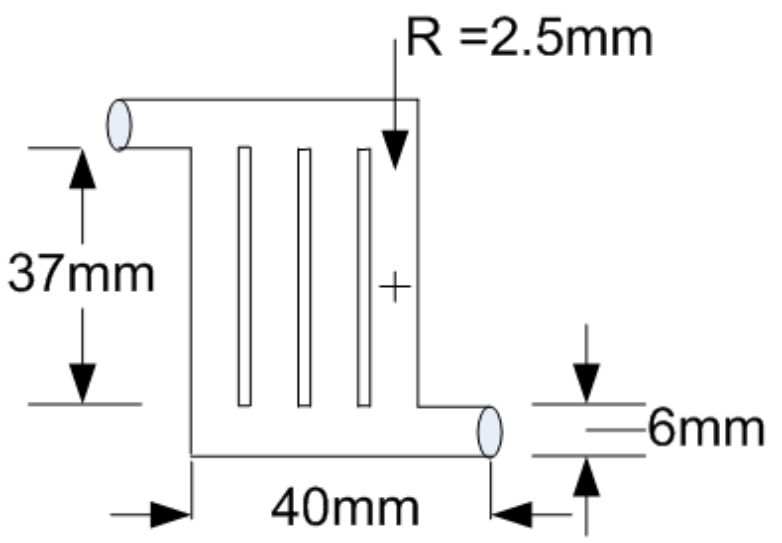

Fig.3. Internal channels of the tested evaporator

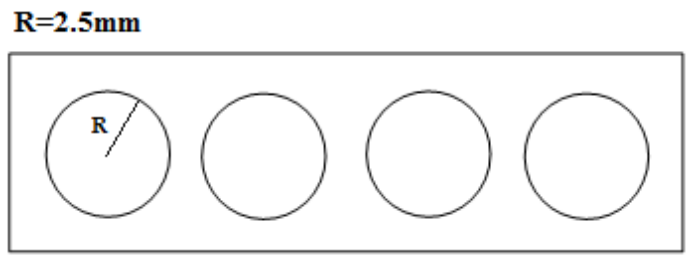

Fig. 4. Top view of the tested evaporator

The dimensions of the internal channels of the evaporator are illustrated in Figs 3 and 4. Four vertical channels with a diameter of $5 \mathrm{~mm}$, length of $37 \mathrm{~mm}$, and total internal surface area of $34.5 \mathrm{~cm}^{2}$. Two cartridge heaters were used in the experiment, each of $250 \mathrm{~W}$ capacity, and they were exactly inserted into two cylindrical holes drilled in the evaporator. To reduce the contact resistance as much as possible between the heaters and the evaporator surfaces, special epoxy material was filled in between.

The power of the heaters was equally distributed to the evaporator channels and was varied in steps from (4-150) $\mathrm{W}$ at natural convection condensation. For this purpose, the heaters were connected to a potentiometer with a solid- state relay. Fig. 5 shows the position of the evaporator's internal channels concerning heaters' holes and shows the direction of refrigerant flow in the system.

The heat supplied from the heaters was assumed to be dissipated through the evaporator without any losses due to the tight fixing of the heaters inside the evaporator as well as the good insulation of the evaporator using $3 \mathrm{~mm}$ thickness rock wool.

2.2 Condenser: An aluminum-finned condenser with the fins oriented vertically that can be cooled by free or forced convection was used. The condenser is $1.32 \mathrm{~m}^{2}$ outside surface area through 120 parallel plates $4.4 \times 25 \mathrm{~cm}$ with 3 mm spacing

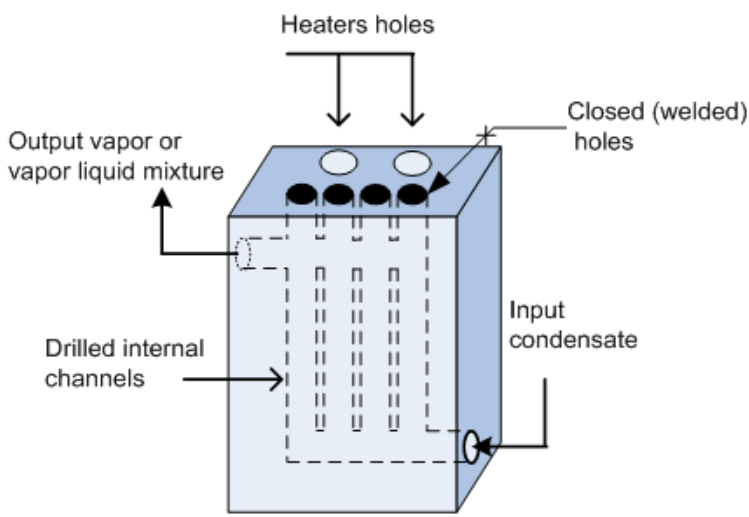

Fig.5. Position of evaporator's internal channels concerning heaters holes

2.3 Riser and down-comer: Both the down-comer and riser were constructed from copper tubing that has high corrosive resistivity against HFCs. The detailed dimensions of the riser and down-comer are illustrated in Fig. 1.

2.4 Sight glass: Two sight glasses were mounted on both the riser and down-comer close to the condenser. The sight glasses gave a clear idea about the fluid phases as well as monitoring any malfunction of the system.

2.5 Measuring devices: The Input heat flux was determined by measuring the voltage and the resistance of each heater using a Fluke 45 Dual Multi-meter. By applying ohms law $\left(P=\frac{V^{2}}{R}\right)$ the input heat flux was calculated. In each measurement, the average values were considered to eliminate the voltage fluctuations, which was less than $2 \%$. Seven K-type thermocouple sensors were attached in the thermosyphon system to monitor the temperatures all over the system. The position of each sensor is illustrated in the schematic diagram of the 
thermosyphon system shown in Fig. 1. The temperature readings were registered by a multi-channel thermometer (Lutron Model: TM-946). Four pressure gauges were used to read the pressures on the inlets and outlets of the evaporator and condenser. Fig. 1 shows the position of each pressure gauge. The pressure readings were recorded. The corresponding saturation temperatures were estimated using saturated liquid-vapor tables for each refrigerant.

2.6 Working fluid: R134a-tetrafluoromethane $\left(\mathrm{CF}_{3} \mathrm{CH}_{2} \mathrm{~F}\right)$ was used in this study. The system was evacuated before charging the refrigerant. At the end of the charging process, the non-condensable gasses were also vented out through the vents at the top of the condenser after heating the system.

\section{RESEARCH METHODOLOGY}

The research methodology was mainly based on an experimental setup of a two-phase closed thermosyphon system built in the laboratory. The effect of heat flux, pressure on the system performance was investigated.

The heat flux was the main manipulated variable during the experimental work. The heat flux steps were 5 to $10 \mathrm{~W}$. The maximum heat flux was always below the critical heat flux (CHF). After the system reaches the steady-state, the temperatures at the designated points were recorded in 10 seconds intervals and then these values were averaged every three minutes

\section{RESULTS ANALYSIS AND DISCUSSION}

\section{1 calculation of heat transfer coefficient at different} heat loads:

The experimental heat transfer coefficient was defined by the ratio of the heat flux and the temperature difference between the evaporator wall and the saturation temperature of the refrigerant as in Eq. (1). Since it was difficult to measure the surface temperature of the channels, it was assumed that the temperature of the inner channel surface was the same as the temperature measured inside the wall near the channel.

$$
h_{\text {exp }}=\frac{\frac{Q}{A}}{T_{e}-T_{\text {sat }}} \cong \frac{\frac{Q}{A}}{T_{S}-T_{\text {sat }}}
$$

Where $\mathrm{Q}$ is heat load $(\mathrm{W}), \mathrm{A}$ is the internal surface area of the evaporator channels $\left(\mathrm{m}^{2}\right), \mathrm{T}_{\mathrm{e}}$ is the surface temperature of the evaporator channel $\left({ }^{\circ} \mathrm{C}\right), \mathrm{T}_{\mathrm{s}}$ is the surface temperature of the evaporator and $\mathrm{T}_{\text {sat }}$ is the saturation temperature at working pressure.

The heat transfer coefficient was affected by errors in the temperature difference between the wall and the fluid and in the heat flux measurement. This temperature difference was compensated in the above equation by subtracting it from the temperature difference between the evaporator wall and the saturation temperature of the refrigerant; it was measured and was found to be neglected from the estimation [1]. The high heat transfer coefficient was greatly dependent on the temperature difference between the evaporator wall and the temperature of the refrigerant in the inside channels.

The heat flux $(\dot{Q})$ exposed to the evaporator is calculated using eq. (2).

$$
\dot{Q}=\frac{Q}{A}
$$

The experimental value of the heat transfer coefficient was studied concerning different reduced pressures.

Fig. 6 shows the heat transfer coefficient versus the heat load dissipated into the evaporator channels using refrigerant R-134a at natural convection (NC) heat transfer mode in the condenser. Eq. (1) is used for calculating the experimental heat transfer coefficient. It is clear that the heat transfer coefficient increases with increasing heat load. 


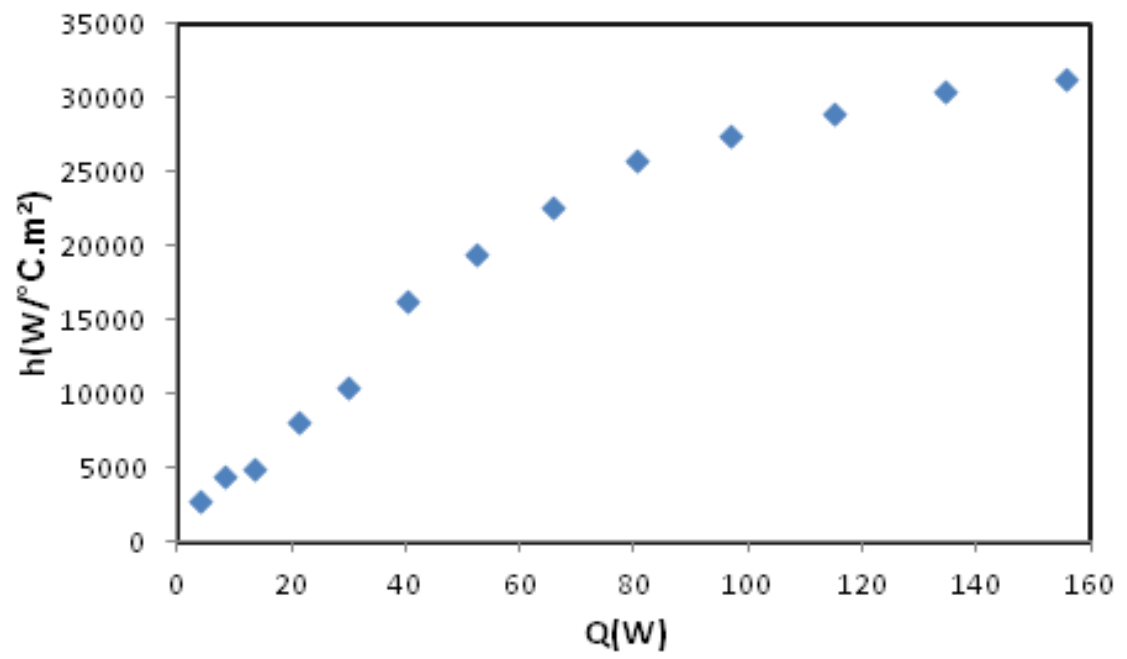

Fig.6. The heat transfer coefficients for R134a at different heat loads using natural convection (NC) mode in the condenser

The direct proportional relation between the heat transfer coefficient and the heat load indicates nucleate heat transfer boiling in the thermosyphon system.

The heat transfer coefficient with free convection cooling mode was higher than the heat transfer coefficient with forced convection $(\mathrm{FC})$ at the same heat loads at low heat loads. This was due to higher saturation pressure in the thermosyphon system at natural convection. This fact appears clearly in Fig. 7, which compares the forced and natural convection heat transfer coefficients. This result agrees with the conclusions obtained in [12].

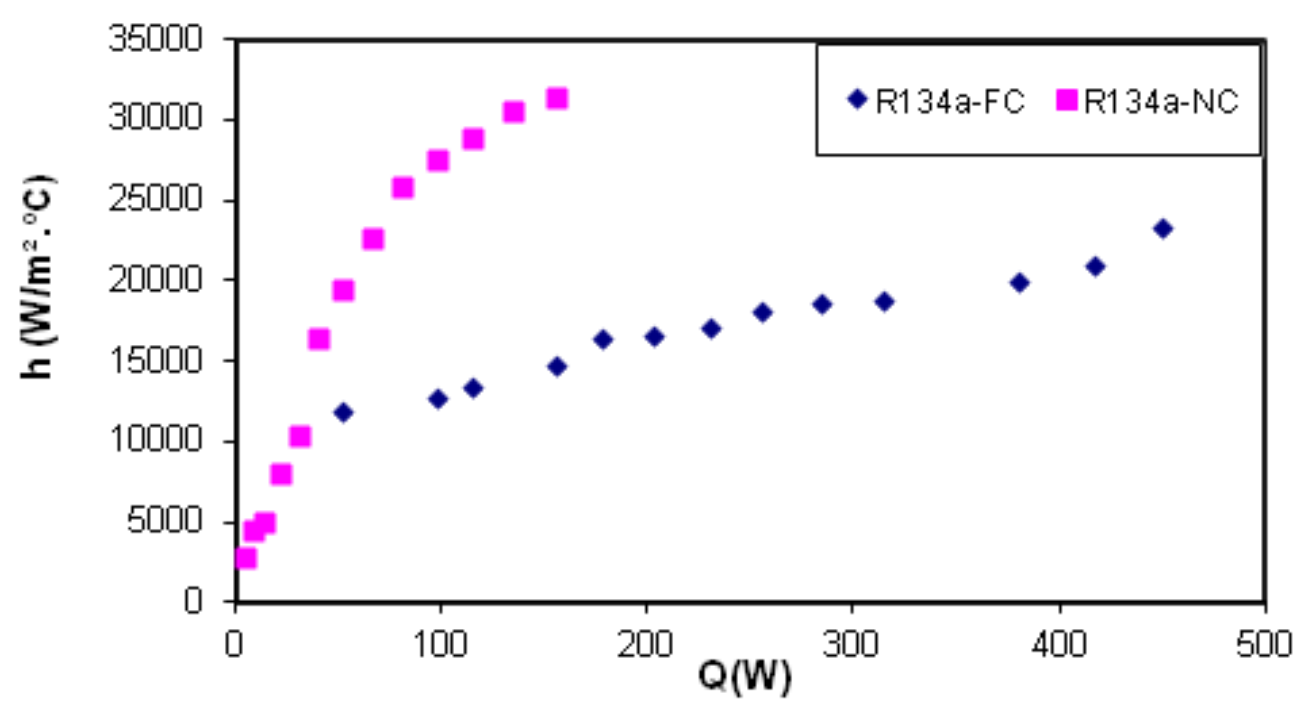

Fig.7.Comparison between heat transfer coefficients for R134a at different heat loads and condenser cooling modes (FC and NC)

Fig. 8 shows the relationship between heat flux and the temperature difference between the evaporator wall and the saturation temperature of the refrigerant inside the channels at the natural convection mode of the condenser. 


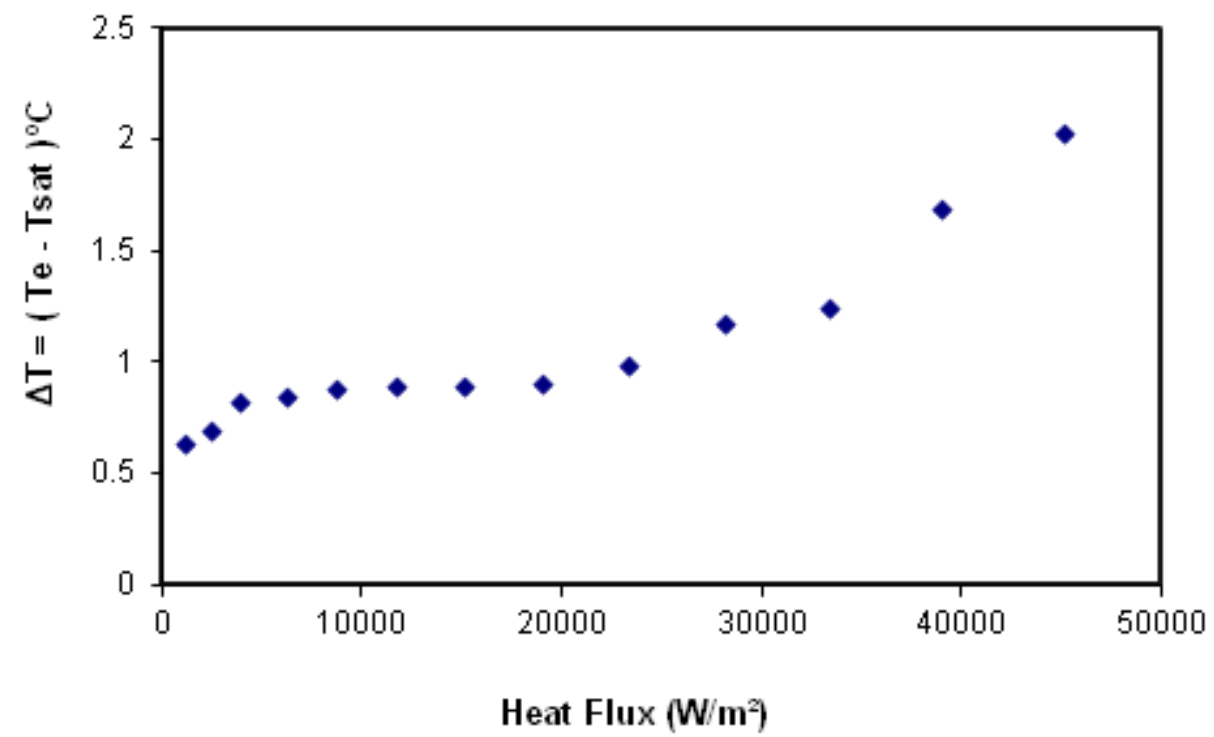

Fig. 8. Heat flux for R134a versus the resulted temperature difference, using natural cooling in the condenser (NC)

4.2 Experimental heat transfer coefficient at different heat loads and reduced pressures.

Fig. 9 illustrates the relationship between the heat transfer coefficient and the heat load at different reduced pressures. It shows that the heat transfer coefficient increases as the reduced pressure increases at different heat loads.

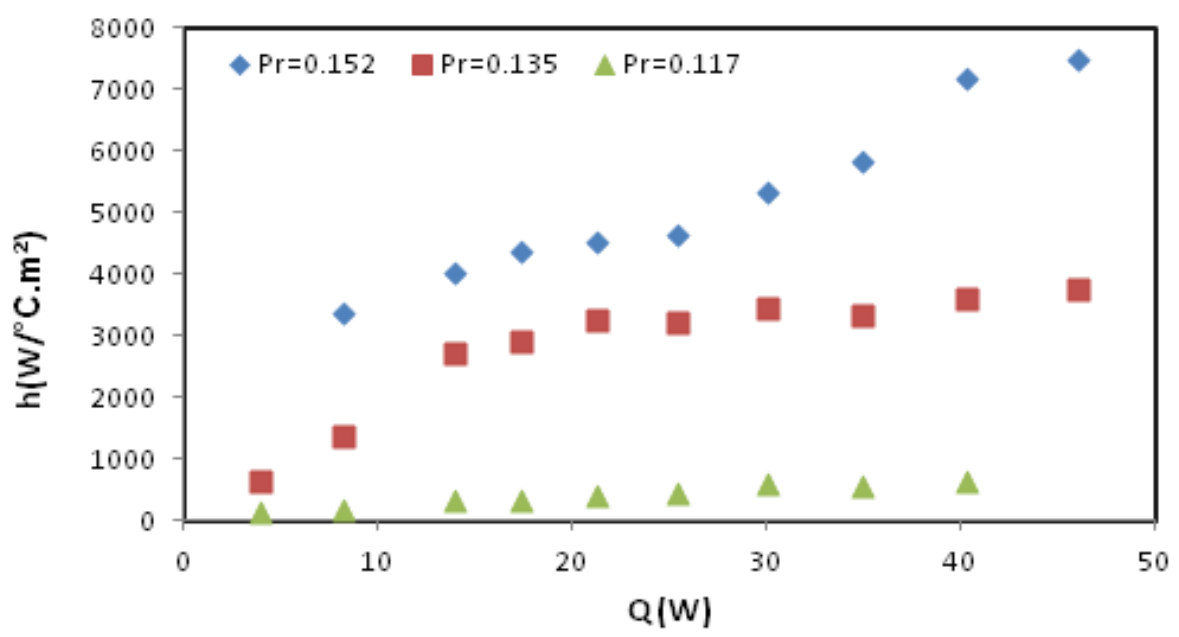

Fig. 9. Comparison between heat transfer coefficients for different reduced pressures at different heat loads

This result had been approved by many researchers who studied the effect of pressure on the boiling heat transfer coefficient. This result can also be generalized for different fluids as the law of corresponding states that variation of thermodynamic and transport properties with reduced pressure was similar for different fluids [1].

Fig. 10 illustrates more clearly the relation between the heat transfer coefficient and the reduced pressure at a specific heat load range. 


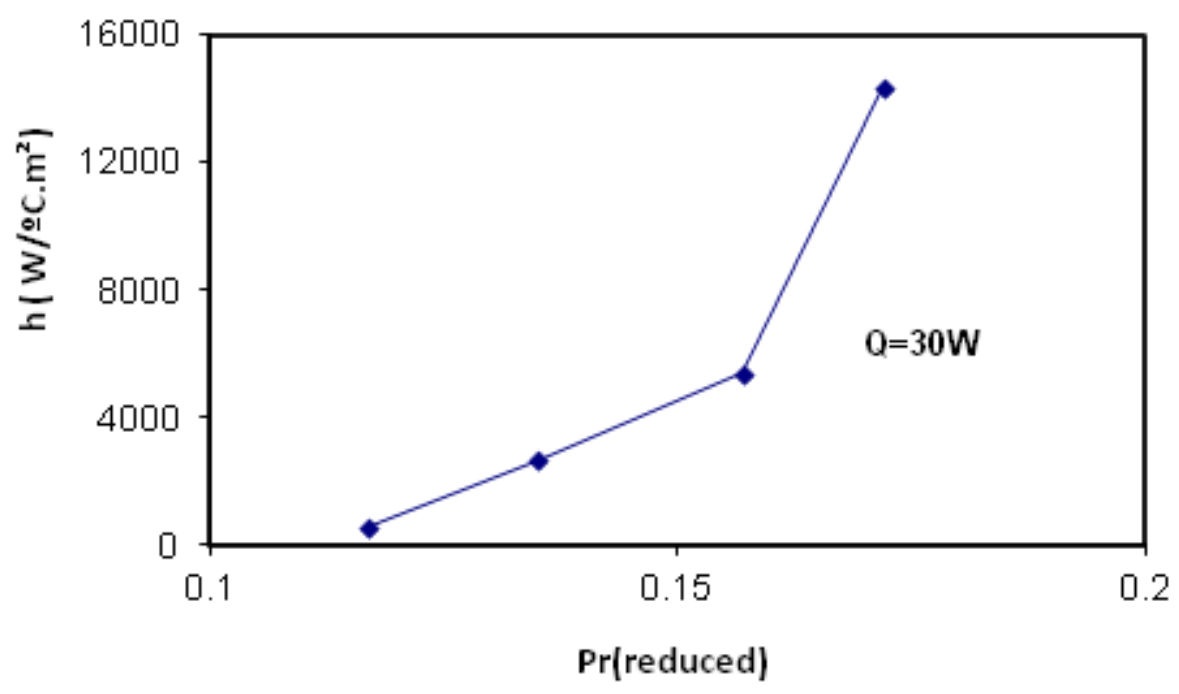

Fig. 10. heat transfer coefficient values $\mathrm{s}$ at different reduced pressure and $50 \mathrm{~W}$ heating load

It can be seen in Figs 9 and 10 that the heat transfer coefficient is promoted by increasing reduced pressure. Several investigators studied the effect of the pressure level on the heat transfer coefficient and proved a similar phenomenon with different refrigerants [19].
The relationship between the heat flux and temperature difference at different reduced pressures is presented in Fig. 11.

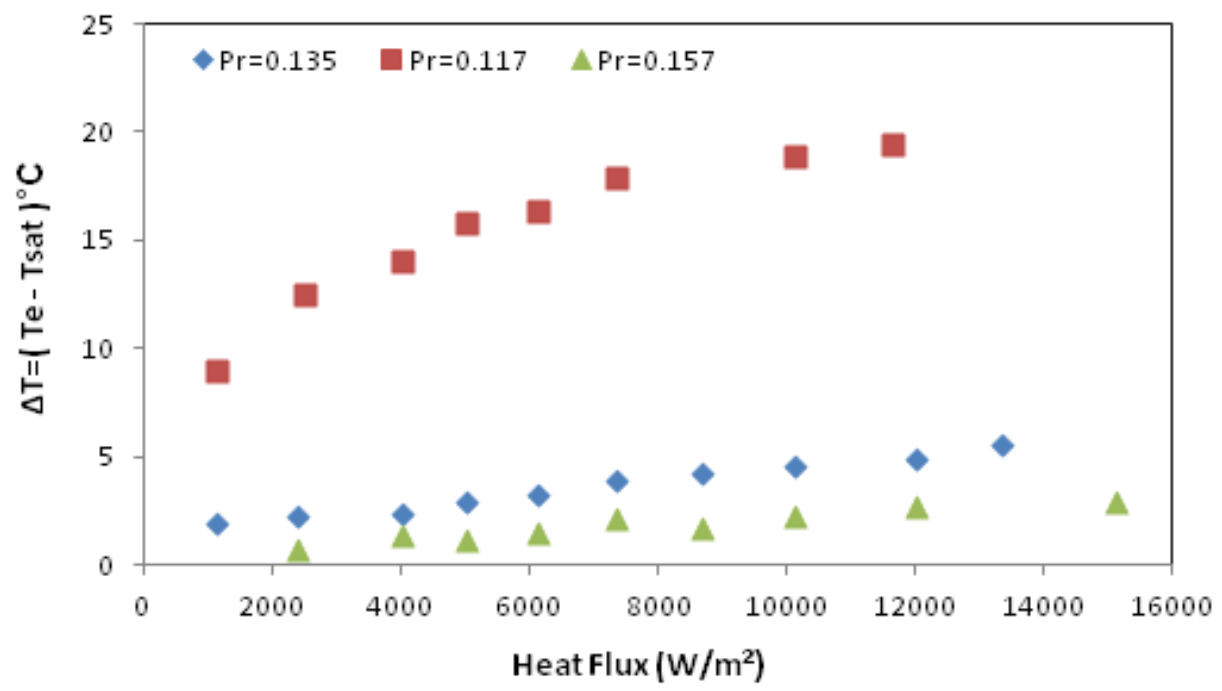

Fig. 11. Relationship between the heat flux and temperature difference at different reduced pressures

It is clear that as the heat flux increases the temperature difference increases but with different slopes depending on the saturation pressure in the thermosyphon system. The heat transfer coefficient increases with increasing saturation pressure. At reduced pressures 0.157 and 0.135 , the maximum temperature difference obtained was $2.9^{\circ} \mathrm{C}$ at $15.2 \mathrm{~kW} / \mathrm{m}^{2}$ and was $5.51^{\circ} \mathrm{C}$ at $13.4 \mathrm{~kW} / \mathrm{m}^{2}$, respectively.

The effect of reduced pressure on the temperature

difference at different heat flux, using Isobutane (R600a) refrigerant had been studied in the literature [1]. It was found that temperature difference decreases as the reduced pressure increases, while the temperature difference increases as the heat flux increases.

\section{CONCLUSIONS}


This study demonstrated that the heat transfer coefficient was directly proportional to the reduced pressure [2]. The temperature difference $\left[\mathrm{T}_{\mathrm{eva}}-\mathrm{T}_{\mathrm{sat}}\right]$ was found to be dependent on both the pressure inside the system and the heat flux applied to the evaporator.

The heat transfer coefficient was highly dependent on the heat applied to the evaporator. It increases linearly with heat applied to the evaporator.

The heat transfer coefficient with free convection condensation was higher than the heat transfer coefficient with forced convection condensation. This has occurred at the same heat load. This was due to higher saturation pressure in the thermosyphon system at natural convection. 


\section{REFERENCES}

[1] R. Khodabandeh, B. Palm, Influence of system pressure on the boiling heat transfer coefficient in a closed two-phase thermosyphon loop, Int. J. Thermal Sci. 41 (2002) 619-624.

[2] Yasin, A. M. M. (2007). Cooling of High Heat Flux Electronic Devices by Two-Phase Thermosyphon System (Master Thesis, An-Najah National University).

[3] L.L.Vasiliev, Micro and miniature heat pipes-electronic component coolers, Applied Thermal Engineering, Elsevier, New York, 28 (2008) 266-273.

[4] P.Chen, Y.Tang, X.K.Liu, Formation of integral fins function surface by extrusion-ploughing process, Transaction of Nonferrous Metals Society of China, The Nonferrous Metals Society of China, Changshao China, vol.11(2006) 1029-1034.

[5] Daraghmeh, H., Sulaiman, M., Yang, K. S., \& Wang, C. C. (2019). Investigation of Separated Two-Phase Thermosiphon Loop for Relieving the Air-Conditioning Loading in Datacenter. Energies, 12(1), 105.

[6] E Abreu, Vasco Tavares Brito. "Test and optimization of a two-phase thermosyphon cooling system for microprocessors under real working conditions." (2017).

[7] Su Dashi; Liu Yajun; Zhou Wei, A new kind of microstructures applied to Closed Loop Thermosyphons, Proceedings of the IEEE International Conference on Mechatronics and Automation, vol., no., (2009) 2167 2172.

[8] Qiusheng Liu, Katsuya Fukuda \& Purwono F. Sutopo, Experimental Study on Thermosyphon for Shipboard High-Power Electronics Cooling System, Heat Transfer Engineering journal, Volume 35, Issue 1112, July 2014, pages 1077-1083.

[9] Yeo, J. , Yamashita, S. , Hayashida, M. and Koyama, S. (2014) A Loop Thermosyphon Type Cooling System for High Heat Flux. Journal of Electronics Cooling and Thermal Control, 4, 128-137. doi: $10.4236 /$ jectc.2014.44014.

[10] Chin Lee Ong, N. Lamaison, J. B. Marcinichen and J. R. Thome, "Two-phase mini-thermosyphon electronics cooling, Part 1: Experimental investigation," 2016 15th IEEE Intersociety Conference on Thermal and Thermomechanical Phenomena in Electronic Systems (ITherm), Las Vegas, NV, USA, 2016, pp. 574-581. doi: 10.1109/ITHERM.2016.7517599.

[11] Bahmanabadi, Amir, Meysam Faegh, and Mohammad Behshad Shafii. "Experimental examination of utilizing novel radially grooved surfaces in the evaporator of a thermosyphon heat pipe." Applied Thermal Engineering 169 (2020): 114975.

[12] R Dobson and J Ruppersberg. Flow and heat transfer in a closed loop thermosyphon. Part I - theoretical simulation, Journal of Energy in Southern Africa, 18 (3) (2007).

[13] R Dobson and J Ruppersberg. Flow and heat transfer in a closed loop thermosyphon. Part II experimental simulation, Journal of Energy in Southern Africa, 18 (3) (2007). 
[14] R. Khodabandeh, Pressure drop in riser and evaporator in an advanced two-phase thermosyphon loop, International Journal of Refrigeration 28 (2005) 725-734.

[15] R. Khodabandeh, Thermal performance of a closed advanced two-phase thermosyphon loop for cooling of radio base stations at different operating conditions, Applied Thermal Engineering 24 (2004) 2643-2655.

[16] B. Palm, R. Khodabandeh, Choosing working fluid for two-phase thermosyphon systems for cooling of electronics, J Electron Packaging, Trans ASME 125 (2003) 276-281.

[17]. Adnan, Samah Ihsan, Aouf Abdulrahman Ahmad, and Adnan Abdulamar Abdulrasool. "Experimental Study of Wickless Heat Pipe with Flat Evaporator for Used in Cooling of Electronic Components." Journal of the University of Babylon for Engineering Sciences 27.2 (2019): 125-137.

[18] Pioro,I. L., D.C. Groenveld, S. C. Cheng, S. Doerffer, A. Z. Vasic, Comparison of CHF measurement in R134a cooled tubes and water CHF look-up table, Int. J. of Heat and Mass Transfer, 44 (2001) 73-88.

[19] Bao, Z. Y., D.F. Fletcher, B.S. Haynes, Flow boiling heat transfer of Freon R11 and HCFC123 in narrow passages", Int. J. of Heat and Mass Transfer, 43 (2000) 3347-335. 